\title{
Thermogravimetric Kinetics of Catalytic Pyrolysis of Sugarcane Bagasse over Nickel-Cerium/HZSM-5 Catalyst
}

\author{
Vekes Balasundram ${ }^{1}$, Khairunnisa Kamarul Zaman², Norazana Ibrahim ${ }^{2, *}$, Rafiziana Md. Kasmani², \\ Ruzinah Isha ${ }^{3}$, Mohd. Kamaruddin Abd. Hamid ${ }^{4}$, Hasrinah Hasbullah ${ }^{4}$ \\ 1 Malaysia-Japan International Institute of Technology (MJIIT), Universiti Teknologi Malaysia, Jalan Sultan Yahya Petra, 54100 Kuala Lumpur, \\ Malaysia \\ 2 Energy Management Research Group, School of Chemical and Energy Engineering, Faculty of Engineering, Universiti Teknologi Malaysia (UTM), \\ 81310 UTM Johor Bahru, Johor, Malaysia \\ 3 Faculty of Chemical \& Natural Resources Engineering, Universiti Malaysia Pahang, 26300, Gambang, Pahang, Malaysia \\ 4 School of Chemical and Energy Engineering, Faculty of Engineering, Universiti Teknologi Malaysia (UTM), 81310 UTM Johor Bahru, Johor, \\ Malaysia
}

\section{ABSTRACT}

The objective of this research is to investigate the performance of Nickel-Cerium/HZSM- 5 catalyst on pyrolysis of sugarcane bagasse and kinetic analysis via thermogravimetric analyzer. The sample is pyrolyzed from 30 to $700{ }^{\circ} \mathrm{C}$ at multiple heating rates $(5,10,20$, and $30{ }^{\circ} \mathrm{C} / \mathrm{min}$ ) in a nitrogen environment. The HZSM-5 was used as a support, while nickel and cerium were impregnated as promoters via incipient wetness impregnation method. For catalytic samples, the catalyst to biomass ratio was fixed at 1:1. The kinetic analysis of non-catalytic and catalytic pyrolysis was performed using the Flynn-Wall-Ozawa and Coats-Redfern methods. The catalytic pyrolysis has achieved higher activation energy $(2.87-68.92 \mathrm{~kJ} / \mathrm{mol})$ over conversion than the non-catalytic pyrolysis $(24.20-122.33 \mathrm{~kJ} / \mathrm{mol})$ using the Flynn-Wall-Ozawa method. The reaction mechanism of non-catalytic and catalytic pyrolysis follows power law $(n=1)$ and chemical reaction $(n=2)$ respectively via the Coats-Redfern method.

\section{Keywords:}

Sugarcane bagasse; Catalytic pyrolysis;

Thermogravimetric analysis; Kinetic

\section{Introduction}

Biomass has widely gained attention from researchers due to the potential as a renewable energy resource, sustainability, environmental concerns, and economic reflection [1]. In addition, the utilization of biomass is very important to preserve the environment from the disposal wastes [2]. Morgan et al., [3] stated that the catalytic pyrolysis of biomass is a highly preferred method to convert biomass materials into renewable fuel energy (bio-fuel), in which can be used as gasoline enhancers in the petrochemical industry and high value-added chemical feedstock. On the other hand, Zhao et al. [4] reported that the Hydrogen exchanged Zeolite Socony Mobil-5 (HZSM-5) catalyst is widely used in oil and chemical industries due to non-corrosiveness, easy preparation, thermal resistant,

\footnotetext{
* Corresponding author.

E-mail address: norazana@utm.my (Norazana Ibrahim)
} 
recyclable, and inexpensive catalyst. Hence, the promising properties of HZSM-5 catalyst have motivated scholars to apply the HZSM-5 catalyst in catalytic pyrolysis of biomass to produce renewable fuel energy [5]. Consequently, the high acidity of HZSM-5 catalyst promotes the formation of coke that easily deactivates the catalyst and reduces the selectivity of hydrocarbons in bio-fuel [6].

Meanwhile, Cheng et al. [7] pointed out that among the metals, nickel ( $\mathrm{Ni}$ ) is the most commonly impregnated on HZSM-5 catalyst for catalytic pyrolysis of biomass due to higher reactivity, low cost, and high availability. Moreover, nickel particles strongly promote the dehydrogenation reaction that favours the formation of hydrocarbons in bio-fuel during catalytic pyrolysis of biomass [8]. In addition, Iliopoulou et al. [9] claimed that the impregnation of nickel on HZSM-5 had significantly improved the selectivity of hydrocarbons in bio-fuel by $37.5 \%$ from HZSM-5 catalyst. Similarly, Veses et al., [10] stated that nickel is a highly reactive metal that enhances the strong Lewis acid sites on HZSM-5 catalyst, in which generate a higher yield of hydrocarbons (35\%) in bio-fuel than HZSM-5 catalyst (29\%). Thus, the acid-catalysing of oxygenates could be further improved with nickel particles on HZSM-5. In contrast, Vichaphund et al., [11] reported that the greater cracking ability of nickel become overwhelming due to the enhanced polymerization (secondary cracking) of volatiles from biomass pyrolysis into heavy compounds, as result settled on the surface of catalyst as coke and blocked the active acid sites of catalyst. Hence, the formation of coke must be solved in order to extend the catalyst's lifetime for more conversion of biomass into hydrocarbons in bio-fuel. Interestingly, Isha and Williams [12] reported that cerium (rare earth metal) has beneficial characteristics of oxygen storage capacity that could suppress the formation of coke during pyrolysis. A recent study by Balasundram et al., [13] stated that the impregnation of cerium as a promoter in HZSM-5 catalyst had significantly enhanced the yield of pyrolysis oil (bio-fuel) and greatly reduced the coke contents than the HZSM-5 catalyst. In addition, rare earth metal could inhibit the dealumination process (removal of aluminium) and desilication (removal of silica) of HZSM-5 during preparation (calcination) [14]. Hence, a higher concentration of acid sites is sustained that improves the cracking activity and thermal stability of rare earth metal modified HZSM-5 catalyst.

Overall, nickel $(\mathrm{Ni})$ has a promising effect on the catalytic pyrolysis of biomass into hydrocarbons, while cerium (Ce) has great influence on suppressing the formation of coke during the upgrading process. For this reason, in this study, nickel and cerium are loaded on $\mathrm{HZSM}-5$ to develop Ni$\mathrm{Ce} / \mathrm{HZSM}-5$ as a multifunctional catalyst for catalytic pyrolysis of sugarcane bagasse via thermogravimetric analyser (TGA). The concept of developing a multifunctional catalyst is to acidcatalysed, deoxygenate, and simultaneously suppress the formation of coke during the catalytic pyrolysis of biomass into hydrocarbons.

Since pyrolysis is about the thermal degradation of biomass in the absence of oxygen, thus it is important to understand the thermal behaviour of biomass prior via thermogravimetric analyser (TGA) before performing the lab-scale or industrial scale biomass pyrolysis. Mishra and Bhaskar [15] stated that the application of TGA is more convenient to predict the thermal behaviours of noncatalytic and catalytic pyrolysis of biomass. Generally, the TGA data is plotted with y-variables of mass change rates and $\mathrm{x}$-variables of temperatures, in which easy to understand the thermal degradation of biomass [16].

In addition, TGA is widely applied to investigate the kinetic parameters of biomass pyrolysis [17]. The advantage of determining the kinetic parameters via TGA is that only fewer data are required for calculating the kinetics over a specific temperature range [18]. TGA-pyrolysis applied the nonisothermal method to evaluate all the kinetic parameters, in which described by an Arrhenius equation [19]. The Flynn-Wall-Ozawa (FWO) and Coats-Redfern (CR) integral methods are most popular and widely used non-isothermal method to describe kinetic parameters of non-catalytic and catalytic pyrolysis of biomass [15]. For example, Guo et al. [20] pointed out that kinetic behaviour of 
biomass pyrolysis was easily interpreted using the FWO and CR integral methods. According to the International Confederation of Thermal Analysis and Calorimetry (ICTAC), the kinetic analysis of solidstate degradation is more accurate and reliable when investigated at multiple heating rates [17]. Meanwhile, White et al. [19] reported that the single heating rate can generate very inconsistent Arrhenius parameters that display a strong dependence on the selected kinetic model. In addition, the FWO method describes the kinetic parameters at multiple heating rates, thus it was first employed in this research to determine the activation energy over the conversion of non-catalytic and catalytic pyrolysis. Next, the CR method was employed to select the best the reaction mechanisms among the seven mechanisms for non-catalytic and catalytic pyrolysis of sugarcane bagasse. On the other hand, Vyazovkin et al. [17] claimed that the lower heating rate $\left(\leq 30^{\circ} \mathrm{C} / \mathrm{min}\right)$ could eliminate the systematic error in activation energy and pre-exponential factor than at higher heating rates in which the difference in sample and reference temperature becomes larger.

To the best of our knowledge, the comprehensive study on the performance of NickelCerium/HZSM-5 catalyst on pyrolysis of sugarcane bagasse and kinetic analysis via thermogravimetric analyzer (TGA) is lacking in the literature. The application of Nickel-Cerium/HZSM-5 catalyst in the catalytic pyrolysis of sugarcane bagasse via thermogravimetric analyser (TGA) becomes the novelty of this research. Therefore, the aim of this research is to evaluate the performance of Ni-Ce/HZSM- 5 catalyst at multiple heating rates $\left(5,10,20\right.$, and $\left.30^{\circ} \mathrm{C} / \mathrm{min}\right)$ on pyrolysis of sugarcane bagasse via thermogravimetric analyser and evaluate the kinetic analysis for catalytic and non-catalytic pyrolysis of sugarcane bagasse. The Flynn-Wall-Ozawa integral method was applied to determine the activation energy $(E)$ over degradation of biomass for non-catalytic and catalytic pyrolysis. In addition, the Coats-Redfern integral method was employed to determine the reaction mechanism of overall non-catalytic and catalytic pyrolysis process. Lastly, the obtained kinetic parameters from Coats-Redfern method were used to validate the experimental data of thermogravimetric and differential thermogravimetric (TG-DTG). This study can be used to determine the design parameters of the catalytic effect on biomass pyrolysis and provide new insight into effectively utilizing the abundant biomass materials.

\section{Materials and methods}

\subsection{Biomass Preparation}

Sugarcane bagasse (SB) sample was selected as biomass pyrolysis feedstock. The SB samples were collected from the local market in Johor, Malaysia. First, the samples were grounded and sieved to obtain a particle size of less than $0.5 \mathrm{~mm}$. Next, the samples were dried at $105 \pm 2{ }^{\circ} \mathrm{C}$ in a microwave oven for about 24 hours until the weight remained constant. The samples were then kept in a desiccator to minimize the absorption of moisture from surrounding humidity. The characterizations of sugarcane bagasse such as proximate analysis, ultimate analysis, and calorific value are reported in our previous work [21].

\subsection{Catalyst Preparation}

The $\mathrm{Ni}-\mathrm{Ce} / \mathrm{HZSM}-5$ multifunctional catalyst was prepared via incipient wetness impregnation (IWI) method. The ZSM-5 $\left(\mathrm{SiO}_{2} / \mathrm{Al}_{2} \mathrm{O}_{3}\right.$ mole ratio $\left.=23\right)$ in ammonium form $\left(\mathrm{NH}^{4+}\right)$ was purchased from Alfa Aesar. Meanwhile, the crystalline powders of Nickel(II) Nitrate Hexahydrate $\left[\mathrm{Ni}_{(}\left(\mathrm{NO}_{3}\right)_{2} .6 \mathrm{H}_{2} \mathrm{O}\right]$ (Purity $=99.0 \%$ ) and Cerium(III) Nitrate Hexahydrate $\left[\mathrm{Ce}\left(\mathrm{NO}_{3}\right)_{3} .6 \mathrm{H}_{2} \mathrm{O}\right.$ ] (Purity $\left.=99.5 \%\right)$ were purchased from ACROS Organics. Firstly, the ZSM-5 $\left(\mathrm{NH}^{4+}\right)$ in ammonium form was converted into the protonic form of $\mathrm{HZSM}-5$ by calcination at a temperature of $600{ }^{\circ} \mathrm{C}$ for 4 hours in the static air 
(ramp rate $=5{ }^{\circ} \mathrm{C} / \mathrm{min}$ ). The calcination was done in laboratory muffle furnace. Next, the impregnation of nickel (Ni) from Nickel(II) Nitrate Hexahydrate and cerium (Ce) from Cerium(III) Nitrate Hexahydrate on HZSM-5 was achieved via incipient wetness impregnation (IWI) method. The weight percent (wt.\%) of catalyst was fixed at 94 wt.\% of HZSM-5, 3 wt.\% of nickel, and 3 wt.\% of cerium based on the highest hydrocarbon contents (\%) from our previous work [13]. After that, all the mass of three chemicals were mixed in a beaker with $80 \mathrm{~mL}$ of deionized water. The solution was well mixed and stirred using magnetic stirrer hot plate at a fixed temperature of $80^{\circ} \mathrm{C}$ for 4 hours. Next, the formed paste was dried in a microwave oven at a temperature of $105 \pm 2{ }^{\circ} \mathrm{C}$ at about 12 hours to remove deionized water. Then, the formed solid catalyst was calcined in a muffle furnace at $600{ }^{\circ} \mathrm{C}$ for 4 hours (ramp rate $=5^{\circ} \mathrm{C} / \mathrm{min}$ ). The characterizations of synthesized catalyst such as XRD, FESEM, BET, FTIR, and TPD-NH ${ }_{3}$ are reported in our previous work [13].

\subsection{TGA-Pyrolysis Experimental Procedure}

The catalytic pyrolysis of sugarcane bagasse over the Nickel-Cerium/HZSM-5 catalyst was conducted via Thermogravimetric Analyzer (TGA/SDTA851, METTLER TOLEDO, USA) according to ASTM D-3172. For comparison, the non-catalytic pyrolysis of sugarcane bagasse was investigated at similar operating conditions. The TGA-pyrolysis of non-catalytic and catalytic pyrolysis of biomass was performed at multiple heating rates $\left(5,10,20\right.$, and $\left.30^{\circ} \mathrm{C} / \mathrm{min}\right)$ under nitrogen $\left(\mathrm{N}_{2}\right)$ atmosphere. The catalytic sample was prepared at a catalyst to biomass mass ratio of $1: 1$ and was well mixed to ensure the uniformity of sample mixture. Then, the prepared non-catalytic and catalytic samples of about 5 mg were first heated to $110{ }^{\circ} \mathrm{C}$ and kept at that temperature for about 30 minutes to remove moisture contents from biomass. After that, the non-catalytic and catalytic samples were individually heated to a maximum temperature of $700{ }^{\circ} \mathrm{C}$ in nitrogen $\left(\mathrm{N}_{2}\right)$ atmosphere flowing at $150 \mathrm{~mL} / \mathrm{min}$. The degradation results of non-catalytic and catalytic samples from TGA were plotted as thermogravimetric and differential thermogravimetric (TG-DTG) curves. The limitation of TGA instrument used in this study is not an online method to directly identify the components of volatile evolved from biomass through the gas chromatography/mass spectrometer (GC/MS) instrument.

\subsection{Kinetic Methods}

According to the International Confederation of Thermal Analysis and Calorimetry (ICTAC), the kinetic analysis of solid-state degradation is more accurate using more than one heating rates [17]. Hence, the Flynn-Wall-Ozawa (FWO) integral method in which varies the heating rates $(5,10,20$, and $30^{\circ} \mathrm{C} / \mathrm{min}$ ) was first applied to determine the activation energy of non-catalytic and catalytic pyrolysis of sugarcane bagasse over conversion (10-90\%). Next, the Coats-Redfern integral method was employed at multiple heating rates $\left(5,10,20\right.$, and $\left.30^{\circ} \mathrm{C} / \mathrm{min}\right)$ to determine the activation energy, pre-exponential factor, and reaction mechanism of non-catalytic and catalytic pyrolysis. In general, the thermal decomposition of biomass can be expressed by the following equation:

$\frac{d \alpha}{d t}=k(T) g(\alpha)$

The Arrhenius equation, $K(T)$ can be defined as in Eq. (2);

$$
k(T)=A \exp \left(-\frac{E}{R T}\right)
$$


Inserting Eq. (2) in Eq. (1) gives;

$\frac{d \alpha}{d t}=A \exp \left(-\frac{E}{R T}\right) g(\alpha)$

For catalytic sample, the $\alpha$ is defined in terms of mass change in the sample (biomass + catalyst) or the mass of volatile generated in Eq. (4), where $w_{o}$ is initial mass sample, $w_{f}$ is final mass sample and $w$ is mass sample at given time. Meanwhile, for non-catalytic sample the $\alpha$ is attributed to the mass change of biomass without catalyst.

$\alpha=\frac{w_{o}-w}{w_{o}-w_{f}}$

In TGA experiments, the heating rate varies as a function of time

$\frac{d \alpha}{d T}=\frac{d \alpha}{d t} \times \frac{d t}{d T}$

For non-isothermal measurements with constant heating rate, $\theta(\theta=d T / d t)$ Eq. (5) can be expressed by the following equation, Eq. (6):

$\frac{d \alpha}{d T}=\frac{d \alpha}{d t} \times \frac{1}{\beta}$

Thus, Eq. (6) is inserted in Eq. (3) gives;

$\frac{d \alpha}{d T}=\frac{A}{\beta} \exp \left(-\frac{E}{R T}\right) g(\alpha)$

where $A$ is the pre-exponential factor, $E$ is the activation energy of the reaction, $R$ is the universal gas constant $(R=8.3144 \mathrm{~J} / \mathrm{K} . \mathrm{mol}), T$ is the absolute temperature, and $g(\alpha)$ is mechanism function. The Flynn-Wall-Ozawa (FWO) integral method further can be expressed from Eq. (7) into Eq. (8). For a given conversion $(\alpha)$, the points of $\log 6$ versus $1000 / T$ can be fitted to a straight line, allowing the activation energy to be determined from the slope of the correlation line.

$\log \beta=\ln \left[\frac{A E}{R G(\alpha)}\right]-2.315-0.4567 \frac{E}{R T}$

The Coats-Redfern integral method can be expressed by logarithm the Eq. (7) and obtained the Eq. (9). The $g(\alpha)$ in Eq. (9) implicates the seven mechanism functions, in which were adopted from literature [16] as shown in Table 1. The satisfactory of function model on reaction was done through examining the linearity (correlation coefficient, $\mathrm{R}^{2}$ ) of $\ln \left[g(\alpha) / T^{2}\right]$ versus $1 / T$ plot. The slope and intercept correspond to $-E / R$ and $\ln (A R / B E)$. Hence, the activation energy and pre-exponential factor can be deduced from the slope and intercept of the straight line.

$\ln \left[\frac{g(\alpha)}{T^{2}}\right]=\ln \frac{A R}{\beta E}\left(1-\frac{2 R T}{E}\right)-\frac{E}{R T}$ 


\section{Table 1}

Reaction model functions and its mechanism [16]

\begin{tabular}{clll}
\hline Model & Model name & Reaction mechanism & $\mathrm{g}(\alpha)$ \\
\hline 1 & Chemical reaction & $\mathrm{n}=1$ & $(1-\alpha)^{-1}$ \\
2 & Chemical reaction & $\mathrm{n}=1.5$ & $6(1-\alpha)^{-1 / 2}$ \\
3 & Chemical reaction & $\mathrm{n}=2$ & $(1-\alpha)^{-1}-1$ \\
4 & Chemical reaction & $\mathrm{n}=3$ & $\left(\left[(1-\alpha)^{-2}-1\right] / 2\right)$ \\
5 & Power law & & $\alpha$ \\
6 & Power law & & $\alpha^{1 / 2}$ \\
7 & Power law & & $\alpha^{1 / 3}$
\end{tabular}

The activation energy values and pre-exponential factors obtained at each reaction mechanisms $[g(\alpha)$ ] from Coats-Redfern method were used to validate the TG mass loss (\%) data from experiment using the Mean Squared Error (MSE). The reaction mechanism with the lowest MSE value implies the accuracy to the result of TG mass loss (\%) from experiment.

\section{Results and Discussions}

\subsection{Effect of Heating Rates}

The TGA-pyrolysis of non-catalytic and catalytic pyrolysis of sugarcane bagasse were plotted as thermogravimetric and differential thermogravimetric (TG-DTG) curves at multiple heating rates (5, 10,20 , and $30^{\circ} \mathrm{C} / \mathrm{min}$ ) as shown in Figs. 1 and 2 respectively. In addition, the TG curve is attributed to the degradation of biomass into the mass loss of volatiles, while the DTG curve is attributed to the degradation rate of biomass pyrolysis. According to Balasundram et al. [16] the TG-DTG curve of TGApyrolysis of biomass could be divided into three phases of biomass degradation such as Phase I (vaporization of moisture and light components) at $30-150{ }^{\circ} \mathrm{C}$, Phase II (devolatization of hemicellulose and cellulose) at $150-450^{\circ} \mathrm{C}$, and Phase III (lignin decomposition) at $450-700{ }^{\circ} \mathrm{C}$. They further claimed that the leftover after $700{ }^{\circ} \mathrm{C}$ can be labelled as solid residual. For better visualization, the TG mass loss (\%) of non-catalytic and catalytic pyrolysis of sugarcane bagasse at multiple heating rates obtained from TG curves were separately plotted in a bar chart as shown in Fig. 3. 

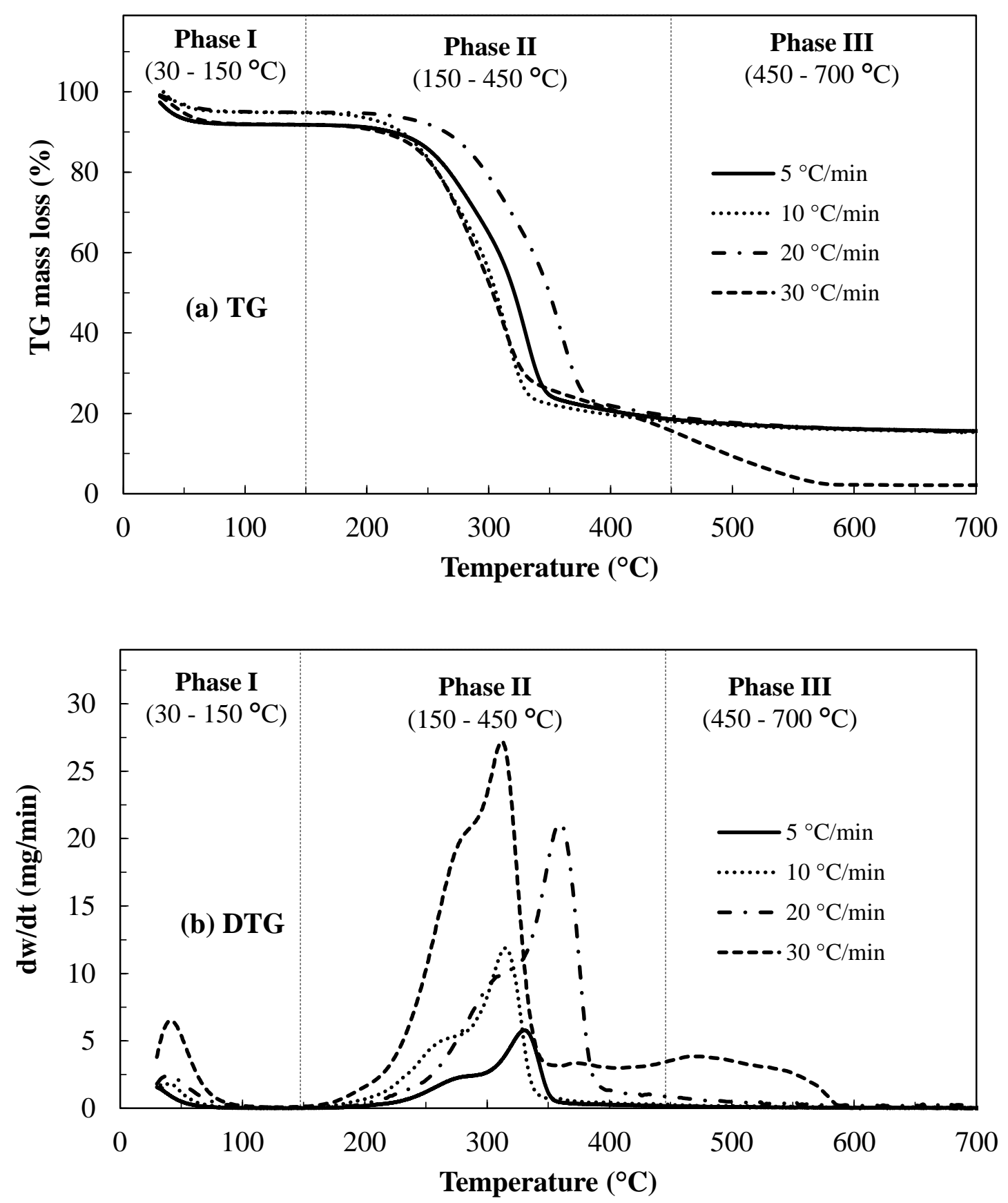

Fig. 1. TG-DTG curves of non-catalytic samples $5,10,20$, and $30^{\circ} \mathrm{C} / \mathrm{min} ;$ (a) TG curve of mass loss and (b) DTG curve

In Phase I, all the samples degraded at TG volatile mass loss of less than $10.0 \%$ as shown in Fig. 3. This is in line with small peaks developed in DTG curve at non-catalytic and catalytic pyrolysis as shown in Figs. 1 and 2 respectively. In addition, the biomass of lower moisture evolution ( $<10.0 \%)$ has an advantage as promising pyrolysis feedstock for higher production of pyrolysis oil [22]. Moreover, moisture content in biomass must be reduced in order to allow heat propagates easily into biomass structure and degrade into higher volatile matter (liquid and gases). In general, moisture is fully composed of water molecules $\left(\mathrm{H}_{2} \mathrm{O}\right)$ that can easily evaporate once reached its boiling point of $100{ }^{\circ} \mathrm{C}$. In addition, some light components of biomass might be evolved together when further increased the temperature up to $150{ }^{\circ} \mathrm{C}$. The increase in heating rate from 5 to $20{ }^{\circ} \mathrm{C} / \mathrm{min}$ had 
decreased the TG mass loss (\%) in Phase I for non-catalytic and catalytic pyrolysis as shown in Fig. 3. However, it was observed that higher TG mass loss was achieved at a higher heating rate of $30^{\circ} \mathrm{C} / \mathrm{min}$ compared at $5-20^{\circ} \mathrm{C} / \mathrm{min}$. This suggests that at a higher heating rate of $30^{\circ} \mathrm{C} / \mathrm{min}$, an additional heat is propagated into the biomass structure that could drove off more moisture contents than at lower heating rate $\left(5-20^{\circ} \mathrm{C} / \mathrm{min}\right)$. On the other hand, it also could be due to easy rupture of the weak chemical bonds at higher heating rate into volatile of light compounds.
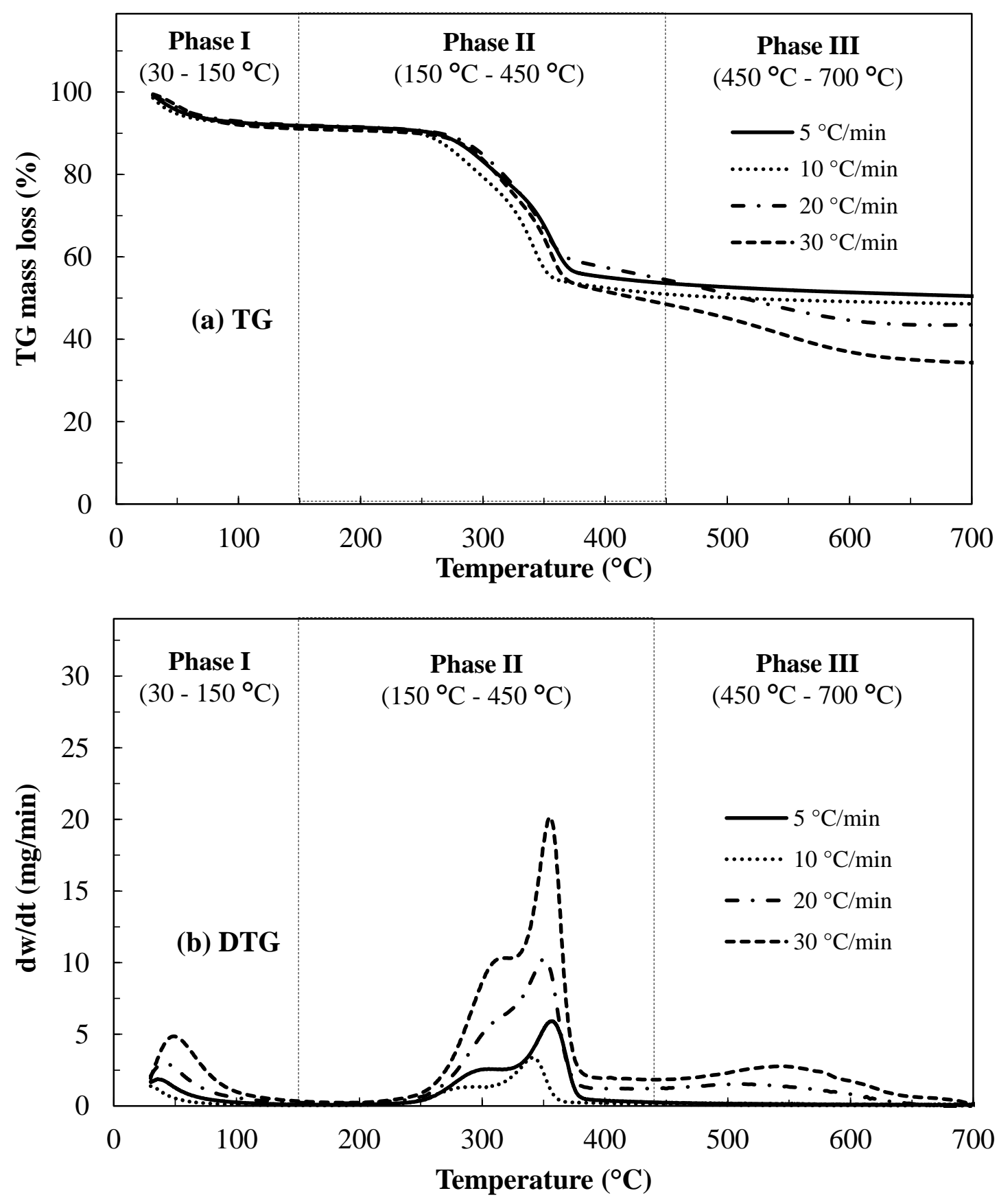

Fig. 2. TG-DTG curves of catalytic samples over $5,10,20$, and $30^{\circ} \mathrm{C} / \mathrm{min}$; (a) TG curve of mass loss and (b) DTG curve 
After Phase I, biomass samples continue to degraded in Phase II $\left(150-450{ }^{\circ} \mathrm{C}\right)$ as shown in TGDTG curves (refer Fig. 1 and 2). In addition, hemicellulose and cellulose are the major components present in biomass. On the other hand, Collard and Blin [23] pointed out that the presence of two peak shoulders in DTG curve is attributed to the degradation of hemicellulose for the first peak shoulder, while the second peak shoulder is attributed to the degradation of cellulose. Moreover, the thermal degradation of hemicellulose mainly occurs within the temperature range of 200-350 ${ }^{\circ} \mathrm{C}$, while the thermal degradation of cellulose mostly occurs at a higher temperature range of 300$390{ }^{\circ} \mathrm{C}$ due to the higher thermal stability than hemicellulose [24]. Similarly, in this study, two peaks were developed in Phase II for non-catalytic (refer Fig. 1) and catalytic pyrolysis (refer Fig. 2). Hence, the higher degradation rate $(\mathrm{dw} / \mathrm{dt})$ of the second peak than the first peak for non-catalytic and catalytic samples suggest that the degradation of cellulose was dominant compared to hemicellulose. Moreover, the higher degradation rate of the second peak might be due to the high compositions of cellulose than hemicellulose in sugarcane bagasse. This is in good agreement with Goenka et al. [25], stating that the presence of high cellulose compositions in biomass has higher degradation rates.

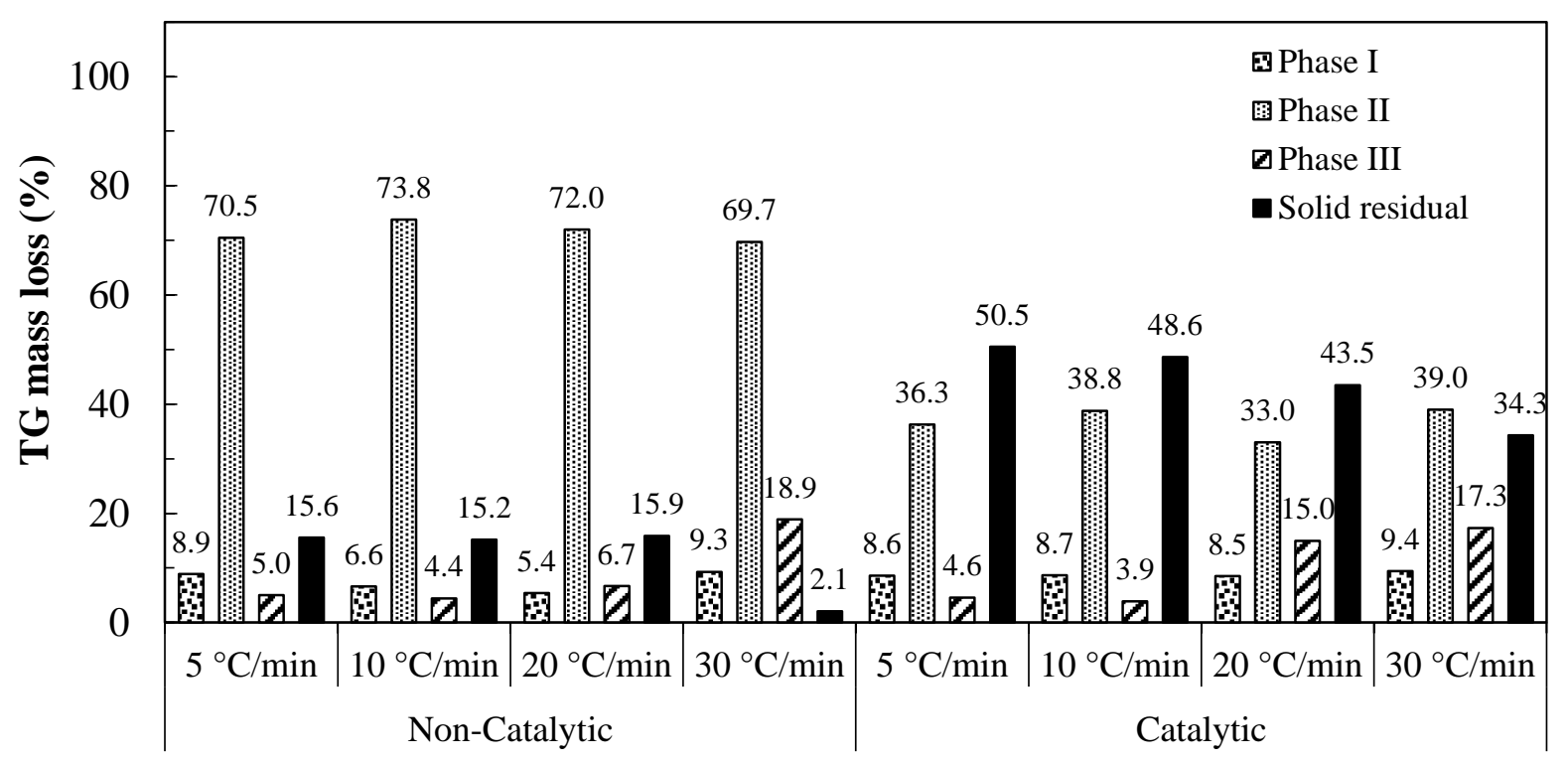

Fig. 3. TG mass loss over $5,10,20$, and $30^{\circ} \mathrm{C} / \mathrm{min}$ for non-catalytic and catalytic samples

Heating rates influence the thermal degradation rate of biomass that developed at different peak temperature points. This suggests that the heating rate influence the pyrolysis of biomass and different trends in the degradation rates (DTG curves) took place when the heating rate is increased from 5 to $30^{\circ} \mathrm{C} / \mathrm{min}$. In addition, the area under the DTG curve becomes wider when the non-catalytic and catalytic pyrolysis is treated at $30{ }^{\circ} \mathrm{C} / \mathrm{min}$ than at $5-20^{\circ} \mathrm{C} / \mathrm{min}$. This explains that the TGApyrolysis of non-catalytic and catalytic samples at $30^{\circ} \mathrm{C} / \mathrm{min}$ had greatly fractured the abundant sidechains attached to the backbone of hemicellulose. The highest TG mass loss (\%) in Phase II was achieved at $10{ }^{\circ} \mathrm{C} / \mathrm{min}(73.8 \%)$ for non-catalytic sample and at $30{ }^{\circ} \mathrm{C} / \mathrm{min}(39.0 \%)$ for the catalytic sample. Moreover, it was observed that the total mass loss of catalytic in Phase II was lower at all heating rates compared to the non-catalytic samples. Hence, the addition of catalyst had significantly reduced the mass loss. This is in line with lower degradation rate occurred at catalytic sample than the non-catalytic sample (refer Fig. 1 (b) and 2 (b)). This explains that the exposures of volatiles on active acid sites of catalyst might be repeatedly polymerized into bulky compounds and deposited on 
the surface of catalyst. Thus, the bulky compounds could accumulate inside the pore passage of catalyst and block the diffusion pathway of volatiles to meet the active acid sites of catalyst. As a result, the trapped bulky compounds might be polymerized into char or coke. This is consistent with the higher content of solid residual leftover at the end of TGA experiment for the catalytic sample than non-catalytic sample (refer Fig. 3).

After Phase II, the biomass continues to degrade in Phase III of lignin degradation at a temperature range of $450-700{ }^{\circ} \mathrm{C}$. Lignin is another chemical composition found in biomass materials and thermally stable than hemicellulose-cellulose structure and yields more char [26]. The highest mass loss of lignin degradation for non-catalytic (18.9\%) and catalytic (17.3\%) samples was achieved at $30^{\circ} \mathrm{C} / \mathrm{min}$. The degradation of lignin in biomass becomes dominant at the higher heating rate that might be due to complex and thermally stable structure than hemicellulose and cellulose [27]. Hence, the higher mass loss in Phase III for non-catalytic and catalytic at $30^{\circ} \mathrm{C} / \mathrm{min}$ than at $5-$ $20^{\circ} \mathrm{C} / \mathrm{min}$ could be due to the enhanced degradation of lignin component in sugarcane bagasse. This is in line with small peaks developed in DTG curve of Phase III for non-catalytic and catalytic samples at $30^{\circ} \mathrm{C} / \mathrm{min}$ as shown in Fig. 1 (b) and Fig. 2 (b) respectively.

After Phase III completed, the leftover was labelled as a solid residual that has not been degraded within the temperature range from 30 to $700{ }^{\circ} \mathrm{C}$ as shown in Fig. 1 and 2. The solid residual is calculated from TG curve by subtracting the total mass loss of Phase I, II and III from $100 \%$ as shown in Fig. 3. The leftover solid residual could be attributed as solid char. As shown in Fig. 3, it was observed that the higher solid residual was leftover at all investigated heating rates for catalytic sample compared to non-catalytic sample. This might be due to the additional deposition of coke materials in the catalytic sample. In detail, the exposures of evolved volatiles on active acid sites of catalyst might be repeatedly polymerized to form coke (carbonaceous material) either on the internal or external surface of the catalyst. The formed coke could block the diffusion pathway of volatiles for reaction along the pore passage that led to the rapid deactivation of the catalyst. These are in a good agreement with the literature reported on the rapid deactivation of the catalyst by coking [28]. As a result, the higher yield of solid residual was leftover at the end of experiment in catalytic samples at all investigates heating rates (see Error! Reference source not found. 3).

Overall, the heating rate has greatly influenced the thermal degradation behaviour of biomass in Phase I, II and III. Thus, the selection of heating rate plays a key role in the degradation of biomass. The major degradation of biomass was occurred in Phase II (cellulose-hemicellulose degradation) for non-catalytic pyrolysis. However, the presence of catalyst had greatly reduced the degradation rate of biomass that might be largely due to the coke formation on the surface of catalyst. Moreover, coke materials influence the reaction mechanism of biomass pyrolysis [29]. Thus, the influence of catalyst mass loading on pyrolysis of biomass could be better illustrated with kinetic parameters.

\subsection{Kinetic Parameters}

According to the International Confederation of Thermal Analysis and Calorimetry (ICTAC) the kinetic analysis of solid state degradation of biomass is more accurate using multiple heating rates [17]. Hence, the Flynn-Wall-Ozawa (FWO) integral method which describes the kinetic parameters of biomass pyrolysis over multiple heating rates $\left(5,10,20\right.$, and $\left.30^{\circ} \mathrm{C} / \mathrm{min}\right)$ was firstly employed to determine the range of activation energy for non-catalytic and catalytic pyrolysis sugarcane bagasse. Next, the Coats-Redfern integral method compromise of seven reaction mechanisms was employed at multiple heating rates $\left(5,10,20\right.$, and $\left.30^{\circ} \mathrm{C} / \mathrm{min}\right)$ to determine the reaction mechanism of catalytic and non-catalytic pyrolysis. Lastly, the activation energy values and pre-exponential factors obtained from Coats-Redfern method were used to validate the TG-DTG curves of actual (experiment) and 
predicted (kinetic model) using the Mean Squared Error (MSE). The reaction mechanism with the lowest MSE value implies the accuracy to the result of TG-DTG curves from experiment and the kinetic parameters obtained from that reaction mechanism was taken as the final value.

\subsubsection{Flynn-Wall-Ozawa (FWO)}

The Flynn-Wall-Ozawa (FWO) method was employed according to the FWO equation (Eq.(8)), resulting in the curves of $\log 6$ versus $1 / T$ for different conversion varying from 10 to $90 \%$ at multiple heating rates $\left(5,10,20\right.$, and $30^{\circ} \mathrm{C} / \mathrm{min}$ ) as illustrated in Fig. 4 ( $\mathrm{a}$ and $\left.\mathrm{b}\right)$. In addition, the FWO method is applied to determine the activation energy on the conversion fraction for non-catalytic (Fig. 4(a)) and catalytic (Fig. 4(b)) pyrolysis of sugarcane bagasse. The correlation of coefficients of non-catalytic and catalytic over conversions $(10-90 \%)$ is $\geq 0.99$. The values of activation energy at different conversion were obtained from the slope of the regression lines and the resulting data were summarized in Fig. 5. In general, the activation energy is defined as the minimum energy required for a reaction to occur in the process. In this research, it was observed that all the investigated samples have positive activation energy over conversion (refer Fig. 5). Hence, it shows that this process is strongly dependent on the reaction temperature.
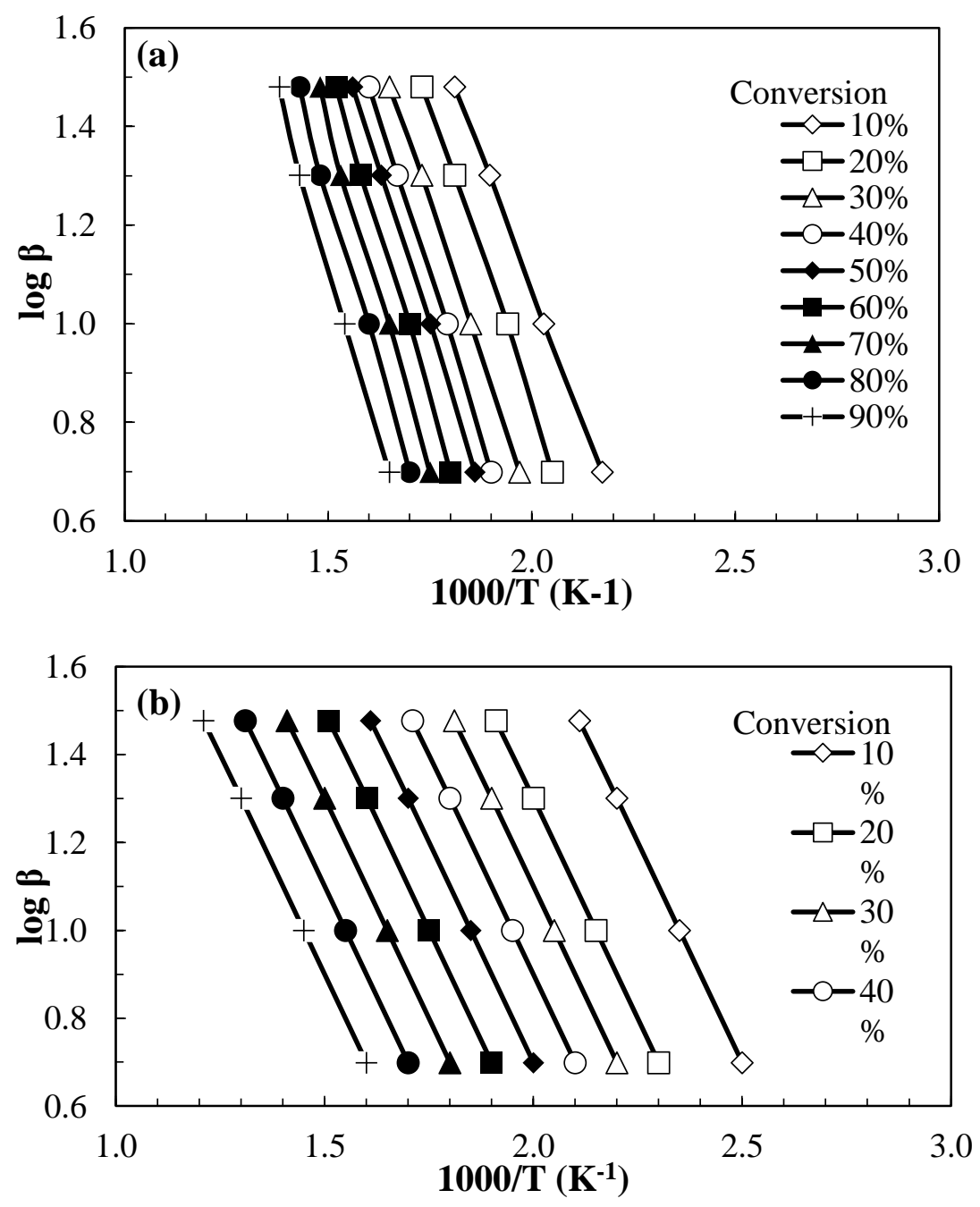

Fig. 4. Regression lines of $\log \beta$ and $1000 / T$ for different conversion; (a) non-catalytic and (b) catalytic pyrolysis 


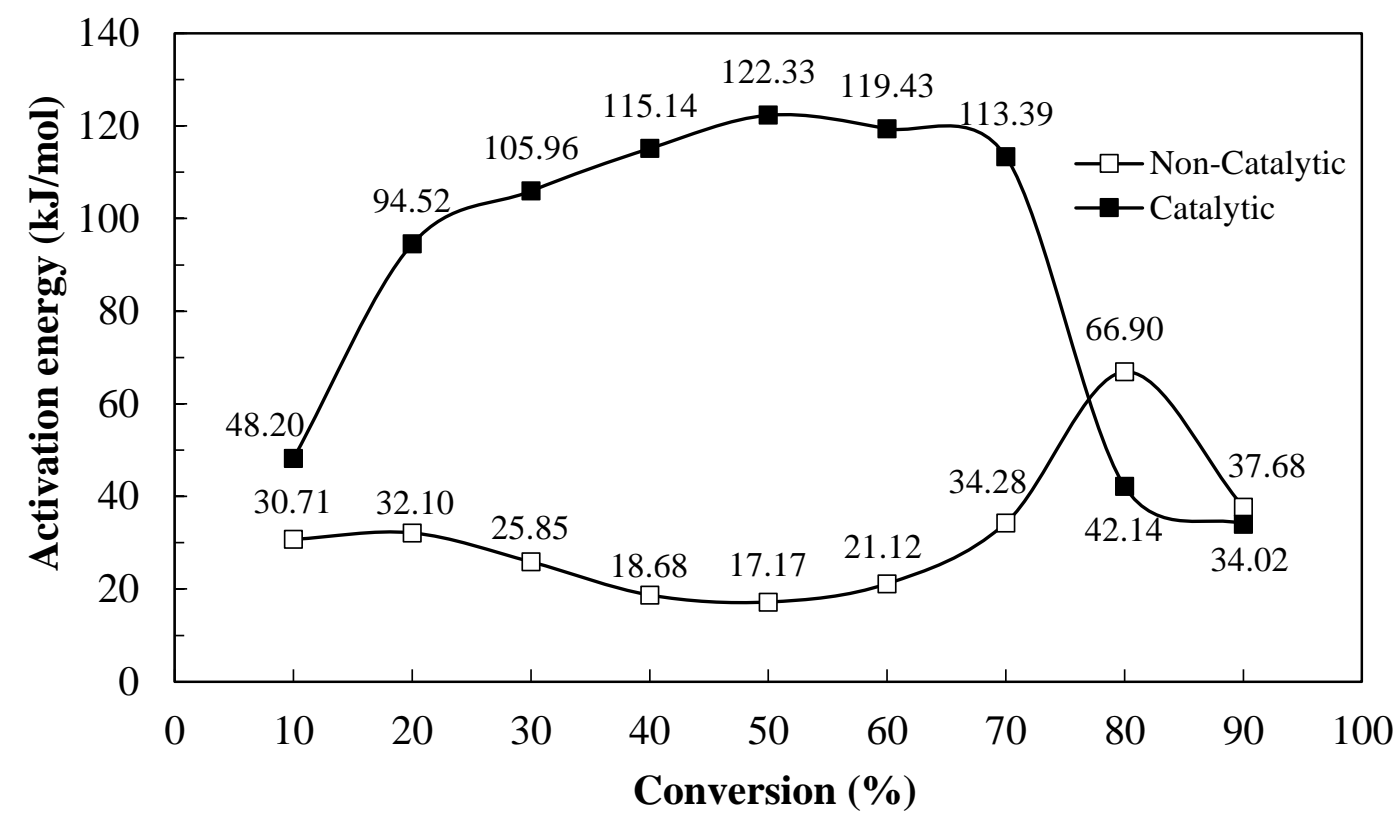

Fig. 5. Activation energy ( $\mathrm{kJ} / \mathrm{mol})$ over conversion (\%)

In addition, the catalyst is widely used in the chemical process due to the strong ability on lowering the activation energy of a process that could directly reduce the capital cost of a process. However, in this research, it was observed that the presence of catalyst has achieved higher activation energy over the conversion from 10 to $80 \%$ compared to the non-catalytic pyrolysis. For example, it was observed that the non-catalytic and catalytic pyrolysis of sugarcane bagasse proceeds with varies activation energy values from $17.17-66.90 \mathrm{~kJ} / \mathrm{mol}$ and $42.14-122.33 \mathrm{~kJ} / \mathrm{mol}$ respectively over conversion (10-80\%). The higher activation energy in catalytic pyrolysis than non-catalytic pyrolysis might be due to the deposition of coke materials on the internal pore passage or external surface area mouth of the catalyst. As a result, the produced coke could increase the activation energy. These are in a good agreement with the literature reported for higher activation energy from catalytic pyrolysis biomass than non-catalytic pyrolysis due to coke burning [25]. Moreover, this in line with DTG curve of catalytic pyrolysis in which developed a small peak in between $420{ }^{\circ} \mathrm{C}$ to 640 ${ }^{\circ} \mathrm{C}$ in Phase III at all heating rates as shown in Fig. 2 (b). Hence, the small peaks could be attributed to the combustion of coke materials at a higher temperature.

Interestingly, the activation energy of non-catalytic pyrolysis of sugarcane bagasse was abruptly increased at $80 \%$ conversion, in which was higher than activation energy of catalytic pyrolysis as shown in Fig. 5. Similarly, the activation energy of non-catalytic pyrolysis at $90 \%$ conversion was higher than catalytic pyrolysis. This might be due to the enhanced degradation of lignin in sugarcane bagasse over conversion, in which in line with DTG curve of non-catalytic pyrolysis at Phase III (refer Fig. 1(b). Meanwhile, the lower activation energy of catalytic pyrolysis of sugarcane bagasse at conversion of $80 \%$ and $90 \%$ might be due to the complete burning of coke materials occurred in between $10 \%$ and $70 \%$. In conclusion, the addition of catalyst in pyrolysis of sugarcane bagasse had enhanced the activation energy over the conversion than non-catalytic pyrolysis. Thus, to better illustrate the influence of catalyst in pyrolysis of sugarcane bagasse, the Coats-Redfern integral method was employed to determine the activation energy, pre-exponential factor, and described the reaction model or mechanism. 


\subsubsection{Coats-Redfern (CR)}

The Coats-Redfern integral method was employed to determine the kinetic parameters such as activation energy, pre-exponential factor, and reaction mechanism of non-catalytic and catalytic pyrolysis. The Arrhenius plots of seven reaction mechanisms $(\ln [g(\alpha)])$ as a function of $1 / T$ were plotted at multiple heating rates $\left(5,10,20\right.$, and $\left.30^{\circ} \mathrm{C} / \mathrm{min}\right)$. The slope of each plot was used to calculate the activation energy $(\mathrm{kJ} / \mathrm{mol})$, while the intercept was used to determine the preexponential factor $\left(\mathrm{min}^{-1}\right)$. The kinetic parameters using Coats-Redfern method determined at multiple heating rates for non-catalytic and catalytic pyrolysis are illustrated in Table 2. The accuracy of the plot was indicated on the basis of linearity characteristics $\left(R^{2}\right)$ for Arrhenius plot. In addition, the mean squared error (MSE) was employed to calculate the error in between actual (experimental) TG mass loss (\%) and predicted (calculated from reaction models) TG mass loss (\%) as shown in Table 3. Since seven reaction mechanisms of the Coats-Redfern integral method were calculated; only the lowest MSE value among the investigated mechanisms was discussed for non-catalytic and catalytic samples. The lowest MSE value indicates the high accuracy of reaction model to the actual (experimental) value.

Table 3 Mean squared error (MSE) between actual and predicted TG-DTG for non-catalytic and catalytic samples

\begin{tabular}{|c|c|c|c|c|}
\hline \multirow[t]{2}{*}{ Model } & \multicolumn{4}{|c|}{ Mean Squared Error (MSE) } \\
\hline & $5^{\circ} \mathrm{C} / \mathrm{min}$ & $10^{\circ} \mathrm{C} / \mathrm{min}$ & $20^{\circ} \mathrm{C} / \mathrm{min}$ & $30^{\circ} \mathrm{C} / \mathrm{min}$ \\
\hline \multicolumn{5}{|c|}{ Non-catalytic } \\
\hline $1^{\mathrm{a}}$ & 38.10 & 45.20 & 54.41 & 74.04 \\
\hline $2^{b}$ & 112.23 & 120.22 & 140.71 & 156.34 \\
\hline $3^{c}$ & 9.56 & 10.33 & 12.95 & 15.63 \\
\hline $4^{d}$ & 12.45 & 15.83 & 22.10 & 25.43 \\
\hline $5^{e}$ & 3.67 & 3.89 & 4.81 & 4.76 \\
\hline $6^{f}$ & 10.56 & 8.98 & 5.69 & 5.12 \\
\hline $7^{\mathrm{g}}$ & 15.34 & 12.68 & 7.35 & 6.86 \\
\hline \multicolumn{5}{|l|}{ Catalytic } \\
\hline $1^{\mathrm{a}}$ & 50.65 & 37.8 & 12.27 & 45.77 \\
\hline $2^{b}$ & 56.75 & 33.86 & 12.24 & 47.96 \\
\hline $3^{c}$ & 5.34 & 5.76 & 6.12 & 4.32 \\
\hline $4^{d}$ & 23.76 & 9.00 & 7.99 & 8.55 \\
\hline $5^{e}$ & 68.74 & 45.23 & 24.06 & 23.87 \\
\hline $6^{f}$ & 42.86 & 32.86 & 24.60 & 27.97 \\
\hline $7^{\mathrm{g}}$ & 78.90 & 56.45 & 25.02 & 47.22 \\
\hline
\end{tabular}

\footnotetext{
${ }^{\text {a }}$ Chemical reaction $(\mathrm{n}=1)$.

${ }^{\mathrm{b}}$ Chemical reaction $(\mathrm{n}=1.5)$.

${ }^{\mathrm{c}}$ Chemical reaction $(\mathrm{n}=2)$.

${ }^{\mathrm{d}}$ Chemical reaction $(\mathrm{n}=3)$.

e Power law $(\mathrm{n}=1)$

${ }^{\mathrm{f}}$ Power law $(\mathrm{n}=2)$.

${ }^{g}$ Power law $(n=3)$
}

As illustrated in Table 3, the lowest MSE value compromise multiple heating rates $(5,10,20$, and $30{ }^{\circ} \mathrm{C} / \mathrm{min}$ ) for non-catalytic pyrolysis of sugarcane bagasse follows the model 5 of power law equation $(n=1)$. Thus, the activation energy for non-catalytic pyrolysis at $5,10,20$, and $30^{\circ} \mathrm{C} / \mathrm{min}$ was achieved at $36.42,44.48,45.71$, and $35.25 \mathrm{~kJ} / \mathrm{mol}$ respectively (refer Table 2 ). In addition, the pre-exponential factor of model 5 at $5,10,20$, and $30^{\circ} \mathrm{C} / \mathrm{min}$ was achieved at $5.54,2.16 \times 10^{1}, 7.14$ $\times 10^{1}$, and $2.26 \times 10^{1} \mathrm{~min}^{-1}$ respectively. The variation in kinetic parameters is due to the degradation of biomass occurred at each heating rates. Thus, the orientation, position, and surface characteristics 
of molecules need to be in a potential well including heat and mass transfer characteristics that play a significant role in completing pyrolysis [25]. In addition, the activation energies obtained at multiple heating rates from Coats-Redfern method (model 5 ) are in line with the range of activation energy over conversion (10-90\%) from Flynn-Wall-Ozawa method. Thus, it can be concluded that the noncatalytic pyrolysis of sugarcane bagasse can be best described using the power law ( $n=1)$.

Interestingly, it was observed that the presence of a catalyst in biomass pyrolysis has changed the pathway of the reaction mechanism, in which the catalytic pyrolysis follows the model 3 of chemical reaction (reaction order $=2$ ) that has the lowest MSE value at all heating rates compared to other reaction models as shown in Table 3. Based on model 3, the presence of catalyst has higher activation energy than non-catalytic sample as shown in Table 2 . Thus, the activation energy for noncatalytic pyrolysis at $5,10,20$, and $30^{\circ} \mathrm{C} / \mathrm{min}$ was achieved at $62.10,78.07,120.76$, and $35.25 \mathrm{~kJ} / \mathrm{mol}$ respectively. In addition, the activation energy from Coats-Redfern method is in line with the activation energy over conversion from Flynn-Wall-Ozawa method for catalytic pyrolysis sample. On the other hand, the catalytic sample (model 3) has a lower pre-exponential factor than the noncatalytic sample (model 5). In general, the pre-exponential factor is directly proportional to the number collisions among molecules during the reaction. Hence, a lower number of collisions among molecules occurred in the catalytic sample that explains the coke materials were highly deposited on the surface of catalyst. This is in good agreement with TG results of catalytic pyrolysis that shows lower degradation of biomass into volatiles mass loss (refer Fig. 3). In conclusion, the activation energy of non-catalytic pyrolysis is lower than the catalytic pyrolysis from Coats-Redfern integral method.

\section{Conclusions}

The thermogravimetric analysis (TGA) has been successfully employed to investigate the performance of Nickel-Cerium/HZSM-5 catalyst on pyrolysis of sugarcane bagasse at $5,10,20$, and $30{ }^{\circ} \mathrm{C} / \mathrm{min}$. The catalytic pyrolysis has achieved lower TG mass loss in Phase II $(33.0-39.0 \%)$ compared to the non-catalytic samples $(73.8-69.7 \%)$. In addition, the catalytic pyrolysis has achieved higher activation energy $(34.02-122.23 \mathrm{~kJ} / \mathrm{mol})$ over conversion than the non-catalytic pyrolysis $(17.17-66.90 \mathrm{~kJ} / \mathrm{mol})$ using the Flynn-Wall-Ozawa method. The reaction mechanisms of non-catalytic and catalytic pyrolysis obtained via the Coats-Redfern method follows power law $(n=1)$ and chemical reaction $(n=2)$ respectively.

\section{Acknowledgements}

The authors would like to acknowledge the financial supports by Universiti Teknologi Malaysia, Ministry of Higher Education (MOHE) of Malaysia (Q.J130000.2546.20H18 and Q.J130000.2546.14H48) and Universiti Malaysia Pahang (RDU1703242).

\section{References}

[1] Bi, Peiyan, Jicong Wang, Yajing Zhang, Peiwen Jiang, Xiaoping Wu, Junxu Liu, He Xue, Tiejun Wang, and Quanxin Li. "From lignin to cycloparaffins and aromatics: directional synthesis of jet and diesel fuel range biofuels using biomass." Bioresource technology 183 (2015): 10-17. https://doi.org/10.1016/i.biortech.2015.02.023

[2] Leng, Shuai, Xinde Wang, Qiuxia Cai, Fengyun Ma, Yue'E. Liu, and Jianguo Wang. "Selective production of chemicals from biomass pyrolysis over metal chlorides supported on zeolite." Bioresource technology 149 (2013): $341-345$. https://doi.org/10.1016/i.biortech.2013.09.096

[3] Morgan Jr, Hervan Marion, Quan Bu, Jianghui Liang, Yujing Liu, Hanping Mao, Aiping Shi, Hanwu Lei, and Roger Ruan. "A review of catalytic microwave pyrolysis of lignocellulosic biomass for value-added fuel and chemicals." Bioresource technology 230 (2017): 112-121. 
https://doi.org/10.1016/j.biortech.2017.01.059

[4] Zhao, Yan, Tao Pan, Yong Zuo, Qing-Xiang Guo, and Yao Fu. "Production of aromatic hydrocarbons through catalytic pyrolysis of 5-hydroxymethylfurfural from biomass." Bioresource technology 147 (2013): 37-42.

https://doi.org/10.1016/i.biortech.2013.07.068

[5] Rezaei Pouya Sirous, Hoda Shafaghat, and Wan Mohd Ashri Wan Daud. "Production of green aromatics and olefins by catalytic cracking of oxygenate compounds derived from biomass pyrolysis: A review." Applied Catalysis A: General 469 (2014): 490-511.

https://doi.org/10.1016/i.apcata.2013.09.036

[6] Wang, Yimeng, and Jie Wang. "Multifaceted effects of HZSM-5 (Proton-exchanged Zeolite Socony Mobil-5) on catalytic cracking of pinewood pyrolysis vapor in a two-stage fixed bed reactor." Bioresource technology 214 (2016): 700-710.

https://doi.org/10.1016/i.biortech.2016.05.027

[7] Cheng Shouyun, Lin Wei, Xianhui Zhao, Yinbin Huang, Douglas Raynie, Changling Qiu, John Kiratu, and Yong Yu. "Directly catalytic upgrading bio-oil vapor produced by prairie cordgrass pyrolysis over Ni/HZSM-5 using a two stage reactor." Aims Energy 3, no. 2 (2015): 227.

https://doi.org/10.3934/energy.2015.2.227

[8] Botas, J. A., D. P. Serrano, A. García, J. De Vicente, and R. Ramos. "Catalytic conversion of rapeseed oil into raw chemicals and fuels over Ni-and Mo-modified nanocrystalline ZSM-5 zeolite." Catalysis today 195, no. 1 (2012): 59-70.

https://doi.org/10.1016/i.cattod.2012.04.061

[9] Iliopoulou, Eleni F., S. D. Stefanidis, K. G. Kalogiannis, A. Delimitis, A. A. Lappas, and K. S. Triantafyllidis. "Catalytic upgrading of biomass pyrolysis vapors using transition metal-modified ZSM-5 zeolite." Applied Catalysis B: Environmental 127 (2012): 281-290.

https://doi.org/10.1016/i.apcatb.2012.08.030

[10] Veses, A., B. Puértolas, M. S. Callén, and T. García. "Catalytic upgrading of biomass derived pyrolysis vapors over metal-loaded ZSM-5 zeolites: Effect of different metal cations on the bio-oil final properties." Microporous and Mesoporous Materials 209 (2015): 189-196. https://doi.org/10.1016/j.micromeso.2015.01.012

[11] Vichaphund, Supawan, Duangdao Aht-ong, Viboon Sricharoenchaikul, and Duangduen Atong. "Production of aromatic compounds from catalytic fast pyrolysis of Jatropha residues using metal/HZSM-5 prepared by ionexchange and impregnation methods." Renewable Energy 79 (2015): 28-37.

https://doi.org/10.1016/j.renene.2014.10.013

[12] Isha, R., and P. T. Williams. "Experimental design methodology for optimising catalytic performance of Ni/Ce/ $\alpha$ Al2O3 catalyst for methane steam reforming." Journal of the Energy Institute 85, no. 1 (2012): 22-28. https://doi.org/10.1179/174396711X13116932752155

[13] Balasundram, Vekes, Khairunnisa Kamarul Zaman, Norazana Ibrahim, Rafiziana Md. Kasmani, Ruzinah Isha, Mohd Kamaruddin Abd Hamid, and Hasrinah Hasbullah. "Catalytic upgrading of pyrolysis vapours over metal modified HZSM-5 via in-situ pyrolysis of sugarcane bagasse: Effect of nickel to cerium ratio on HZSM-5." Journal of Analytical and Applied Pyrolysis 134 (2018): 309-325. https://doi.org/10.1016/i.jaap.2018.06.021

[14] Momayez, Forough, Jafar Towfighi Darian, and Seyedeh Mahboobeh Teimouri Sendesi. "Synthesis of zirconium and cerium over HZSM-5 catalysts for light olefins production from naphtha." Journal of analytical and applied pyrolysis 112 (2015): 135-140.

https://doi.org/10.1016/j.jaap.2015.02.006

[15] Mishra Garima, and Thallada Bhaskar. "Non isothermal model free kinetics for pyrolysis of rice straw." Bioresource technology 169 (2014): 614-621. https://doi.org/10.1016/j.biortech.2014.07.045

[16] Balasundram, Vekes, Norazana Ibrahim, Rafiziana Md Kasmani, Mohd Kamaruddin Abd Hamid, Ruzinah Isha, Hasrinah Hasbullah, and Roshafima Rasit Ali. "Thermogravimetric catalytic pyrolysis and kinetic studies of coconut copra and rice husk for possible maximum production of pyrolysis oil." Journal of cleaner production 167 (2017): 218-228.

https://doi.org/10.1016/i.jclepro.2017.08.173

[17] Vyazovkin, Sergey, Alan K. Burnham, José M. Criado, Luis A. Pérez-Maqueda, Crisan Popescu, and Nicolas Sbirrazzuoli. "ICTAC Kinetics Committee recommendations for performing kinetic computations on thermal analysis data." Thermochimica acta 520, no. 1-2 (2011): 1-19.

https://doi.org/10.1016/i.tca.2011.03.034 
[18] Yiin, Chung Loong, Suzana Yusup, Armando T. Quitain, Yoshimitsu Uemura, Mitsuru Sasaki, and Tetsuya Kida. "Thermogravimetric analysis and kinetic modeling of low-transition-temperature mixtures pretreated oil palm empty fruit bunch for possible maximum yield of pyrolysis oil." Bioresource technology 255 (2018): 189-197. https://doi.org/10.1016/i.biortech.2018.01.132

[19] White, John E., W. James Catallo, and Benjamin L. Legendre. "Biomass pyrolysis kinetics: a comparative critical review with relevant agricultural residue case studies." Journal of analytical and applied pyrolysis 91, no. 1 (2011): 1-33. https://doi.org/10.1016/i.jaap.2011.01.004

[20] Guo, Feiqiang, Yuping Dong, Zhaochuan Lv, Pengfei Fan, Shuai Yang, and Lei Dong. "Pyrolysis kinetics of biomass (herb residue) under isothermal condition in a micro fluidized bed." Energy conversion and management 93 (2015): 367-376. https://doi.org/10.1016/i.enconman.2015.01.042

[21] Vekes Balasundram, Noorhaza Alias, Norazana Ibrahim, Rafiziana Md Kasmani, Mohd Kamaruddin Abd Hamid, Ruzinah Isha, and Hasrinah Hasbullah. Thermal Characterization of Malaysian Biomass via Thermograviemtric Analysis. Journal of Energy and Safety Technology 1 (2018): 31-38. https://doi.org/10.11113/jest.v1n1.6

[22] Van de Velden, Manon, Jan Baeyens, Anke Brems, Bart Janssens, and Raf Dewil. "Fundamentals, kinetics and endothermicity of the biomass pyrolysis reaction." Renewable energy 35, no. 1 (2010): 232-242. https://doi.org/10.1016/i.renene.2009.04.019

[23] Collard, F., Blin, J. A review on pyrolysis of biomass constituents: Mechanism and composition of the products obtained from the conversion of cellulose, hemicellulose and lignin. Renewable and Sustainable Energy Reviews 38 (2014): 294-608.

https://doi.org/10.1016/i.rser.2014.06.013

[24] Pham, Tu Nguyet, Dachuan Shi, and Daniel E. Resasco. "Evaluating strategies for catalytic upgrading of pyrolysis oil in liquid phase." Applied Catalysis B: Environmental 145 (2014): 10-23. https://doi.org/10.1016/i.apcatb.2013.01.002

[25] Goenka, Reeshab, Prakash Parthasarathy, Naveen Kumar Gupta, Navneet Kumar Biyahut, and Sheeba Narayanan. "Kinetic analysis of biomass and comparison of its chemical compositions by thermogravimetry, wet and experimental furnace methods." Waste and biomass valorization 6, no. 6 (2015): 989-1002.

https://doi.org/10.1007/s12649-015-9402-3

[26] Fan, Liangliang, Paul Chen, Nan Zhou, Shiyu Liu, Yaning Zhang, Yuhuan Liu, Yunpu Wang et al. "In-situ and ex-situ catalytic upgrading of vapors from microwave-assisted pyrolysis of lignin." Bioresource technology 247 (2018): 851-858. https://doi.org/10.1016/j.biortech.2017.09.200

[27] Pham, Tu N., Tawan Sooknoi, Steven P. Crossley, and Daniel E. Resasco. "Ketonization of carboxylic acids: mechanisms, catalysts, and implications for biomass conversion." Acs Catalysis 3, no. 11 (2013): 2456-2473. https://doi.org/10.1021/cs400501h

[28] Veses, A., M. Aznar, I. Martínez, J. D. Martínez, J. M. López, M. V. Navarro, M. S. Callén, R. Murillo, and T. García. "Catalytic pyrolysis of wood biomass in an auger reactor using calcium-based catalysts." Bioresource technology 162 (2014): 250-258. https://doi.org/10.1016/i.biortech.2014.03.146

[29] Veses, A., B. Puértolas, M. S. Callén, and T. García. "Catalytic upgrading of biomass derived pyrolysis vapors over metal-loaded ZSM-5 zeolites: Effect of different metal cations on the bio-oil final properties." Microporous and Mesoporous Materials 209 (2015): 189-196. https://doi.org/10.1016/i.micromeso.2015.01.012 
Table 2 Kinetics parameters for non-catalytic and catalytic pyrolysis at multiple heating rates using Coats-Redfern method.

\begin{tabular}{|c|c|c|c|c|c|c|c|c|}
\hline \multirow[t]{2}{*}{ Model } & \multicolumn{2}{|c|}{$5^{\circ} \mathrm{C} / \mathrm{min}$} & \multicolumn{2}{|c|}{$10{ }^{\circ} \mathrm{C} / \mathrm{min}$} & \multicolumn{2}{|c|}{$20{ }^{\circ} \mathrm{C} / \mathrm{min}$} & \multicolumn{2}{|c|}{$30{ }^{\circ} \mathrm{C} / \mathrm{min}$} \\
\hline & $\begin{array}{c}\mathrm{E} \\
(\mathrm{kJ} / \mathrm{mol})\end{array}$ & $\begin{array}{c}\mathrm{A} \\
\left(\mathrm{min}^{-1}\right)\end{array}$ & $\begin{array}{c}\mathrm{E} \\
(\mathrm{kJ} / \mathrm{mol})\end{array}$ & $\begin{array}{c}\mathrm{A} \\
\left(\mathrm{min}^{-1}\right)\end{array}$ & $\begin{array}{c}\mathrm{E} \\
(\mathrm{kJ} / \mathrm{mol})\end{array}$ & $\begin{array}{c}\mathrm{A} \\
\left(\mathrm{min}^{-1}\right)\end{array}$ & $\begin{array}{c}\mathrm{E} \\
(k J / m o l)\end{array}$ & $\begin{array}{c}\mathrm{A} \\
\left(\min ^{-1}\right)\end{array}$ \\
\hline \multicolumn{9}{|c|}{ Non-catalytic } \\
\hline $1^{\mathrm{a}}$ & 47.71 & $1.23 \times 10^{2}$ & 52.6 & $9.92 \times 10^{2}$ & 68.43 & $3.92 \times 10^{4}$ & 97.60 & $9.54 \times 10^{6}$ \\
\hline $2^{\mathrm{b}}$ & 8.80 & 2.08 & 11.76 & 9.81 & 19.69 & $7.45 \times 10^{1}$ & 34.70 & $2.23 \times 10^{3}$ \\
\hline $3^{c}$ & 87.34 & $1.74 \times 10^{6}$ & 101.04 & $2.82 \times 10^{6}$ & 119.12 & $1.83 \times 10^{5}$ & 145.36 & $2.45 \times 10^{7}$ \\
\hline $4^{\mathrm{d}}$ & 152.35 & $3.02 \times 10^{8}$ & 171.31 & $1.71 \times 10^{7}$ & 206.87 & $6.47 \times 10^{10}$ & 264.09 & $5.49 \times 10^{15}$ \\
\hline $5^{\mathrm{e}}$ & 36.42 & 5.54 & 44.48 & $2.16 \times 10^{1}$ & 45.71 & $7.14 \times 10^{1}$ & 35.25 & $2.26 \times 10^{1}$ \\
\hline $6^{\mathrm{f}}$ & 17.11 & $6.37 \times 10^{-2}$ & -4.88 & $-1.87 \times 10^{-1}$ & -3.70 & $-5.48 \times 10^{-1}$ & -6.17 & $-2.76 \times 10^{-1}$ \\
\hline $7^{\mathrm{g}}$ & 10.66 & $9.93 \times 10^{-3}$ & -19.94 & $-2.70 \times 10^{-2}$ & -12.14 & $-4.98 \times 10^{-2}$ & -13.81 & $-6.00 \times 10^{-3}$ \\
\hline \multicolumn{9}{|c|}{ Catalytic } \\
\hline $1^{\mathrm{a}}$ & 24.81 & 3.84 & 41.68 & $8.03 \times 10^{1}$ & 92.80 & $5.37 \times 10^{6}$ & 61.70 & $3.36 \times 10^{4}$ \\
\hline $2^{\mathrm{b}}$ & -11.37 & $-1.13 \times 10^{-1}$ & 9.42 & 2.37 & 31.66 & $1.20 \times 10^{3}$ & 16.31 & $8.94 \times 10^{1}$ \\
\hline $3^{c}$ & 62.10 & $6.56 \times 10^{2}$ & 78.07 & $1.55 \times 10^{4}$ & 120.76 & $1.19 \times 10^{7}$ & 107.46 & $8.32 \times 10^{4}$ \\
\hline $4^{\mathrm{d}}$ & 106.77 & $8.21 \times 10^{4}$ & 138.34 & $7.55 \times 10^{7}$ & 299.08 & $5.27 \times 10^{18}$ & 187.14 & $3.46 \times 10^{10}$ \\
\hline $5^{\mathrm{e}}$ & 8.24 & $5.16 \times 10^{-1}$ & 4.57 & 1.89 & 13.15 & 1.66 & 16.68 & 2.65 \\
\hline $6^{f}$ & -10.43 & $-8.24 \times 10^{-3}$ & -10.91 & $-3.25 \times 10^{-1}$ & -7.95 & $-2.70 \times 10^{-2}$ & -6.21 & $-5.05 \times 10^{-2}$ \\
\hline $7^{\mathrm{g}}$ & -16.63 & $-4.41 \times 10^{-3}$ & -16.97 & $-7.00 \times 10^{-3}$ & -14.97 & $-1.82 \times 10^{-2}$ & -13.83 & $-2.51 \times 10^{-2}$ \\
\hline $\begin{array}{l}{ }^{a} \mathrm{Ch} \\
{ }^{\mathrm{b}} \mathrm{Ch} \\
{ }^{\mathrm{c}} \mathrm{Ch} \\
{ }^{\mathrm{d}} \mathrm{Ch} \\
{ }^{\mathrm{e}} \mathrm{Pov} \\
{ }^{\mathrm{f}} \mathrm{Pov} \\
{ }^{\mathrm{g}} \mathrm{Pov}\end{array}$ & $\begin{array}{l}\text { ical reaction } \\
\text { ical reaction } \\
\text { ical reaction } \\
\text { ical reaction } \\
\text { law }(n=1) \text {. } \\
\text { law }(n=2) \text {. } \\
\text { law }(n=3) \text {. }\end{array}$ & $\begin{array}{l}=1) . \\
=1.5) . \\
=2) . \\
=3) .\end{array}$ & & & & & & \\
\hline
\end{tabular}

